\title{
Prevalence of Methicillin Resistance Staphylococcus aureus in Teaching Hospital, Karnataka, India
}

\author{
R. Sharlee ${ }^{1}$ and B. Sumangala ${ }^{2^{*}}$ \\ ${ }^{1}$ Department of Microbiology, Chamarajnagar Institute Medical Sciences, \\ Chamarajanagar, Karnataka, India \\ ${ }^{2}$ Department of Microbiology, Mandya Institute Medical Sciences, \\ Mandya, Karnataka, India \\ *Corresponding author
}

\section{A B S T R A C T}

Methicillin-resistant Staphylococcus aureus (MRSA) is relatively ubiquitous and the cause of community acquired colonization and infections as well as endemic and epidemic nosocomial colonization and infections. Early detection of MRSA

\section{Keywords}

Staphylococcus aureus, MRSA, MSSA

\section{Article Info}

Accepted:

22 February 2020

Available Online: 10 March 2020 and formulation of an effective antibiotic policy, along with infection control in tertiary care hospitals is of paramount importance from an epidemiological viewpoint. Present study was carried out to know the prevalence MRSA infection in teaching hospital located in Karnataka One hundred fifty isolates from clinical samples were processed. Colonies suggestive of Staphylococcus aureus were

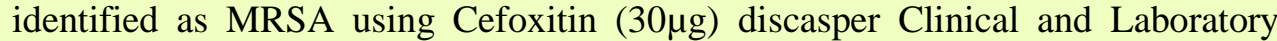
Standards Institute (CLSI) guidelines. In our study out of 150 isolates of Staphylococcus aureus, 65(43.3\%) were MRSA and 85(56.7\%) were MSSA. MRSA infections were noticed high in the age group $<14$ yrs $(80 \%)$ and have high $(67.7 \%)$ prevalence among male patients. Different studies show different rate of isolation of MRSA, this might be due to antibiotic policy \& antibiotic pressure vary from hospital to hospital, different time period of studies and difference in their location. Difference in the socioeconomic status of study group between hospitals.

\section{Introduction}

Staphylococcus aureus is the most clinically significant species of Staphylococci has been recognized as an important cause of human disease for more than 100 years. ${ }^{1}$ It is one of the pathogens of greatest concern because of its intrinsic virulence factors, its ability to cause diverse array of life threatening infections, it's competency to adapt to different environmental conditions and its nasal carriage, which accounts for possible 
spread and re infection. ${ }^{2}$ It is one among the top three major potential pathogens responsible for community and hospital acquired infections causing diseases ranging from relatively minor skin and soft tissue infections primarily to life-threatening systemic infections which can be either toxin/non-toxin mediated, leading to high morbidity and mortality throughout the world. $^{3,4}$

Staphyloccus aureus is of increasing risk in the medical community due to the emergence of multiple antibiotic resistances. MRSA strains were first reported in 1961, soon after methicillin entered clinical use. ${ }^{5}$

Outbreaks of infections caused by MRSA were reported soon thereafter in Europe, and by the mid-1970s, MRSA had become a significant problem in the United States. ${ }^{5}$

MRSA strains are critical public health threats because they cause hospital-acquired infections that can be difficult and expensive to treat. Many MRSA strains are susceptible only to vancomycin, and this antibiotic is used extensively to treat patients infected with these organisms.

Hence, there is also concern that MRSA may serve as a reservoir of organisms that may give rise to vancomycin-resistant strains that could not be killed by available antibiotics. ${ }^{5}$

Methicillin-resistant Staphylococcus aureus (MRSA) is relatively ubiquitous and the cause of community acquired colonization and infections as well as endemic and epidemic nosocomial colonization and infections. ${ }^{6}$

Early detection of MRSA and formulation of an effective antibiotic policy, along with infection control in tertiary care hospitals is of paramount importance from an epidemiological viewpoint.
Present study was carried out to know the prevalence MRSA infection in teaching hospital located in Karnataka.

\section{Materials and Methods}

\section{Study setting}

The study was carried in Department of microbiology, Mandya Institute of medical Sciences, Mandya, Karnataka

\section{Study design}

Cross sectional study

\section{Study period}

January 2017 to December 2017

\section{Sample size}

150 Samples

\section{Source of data}

All isolates of Staphylococcus aureus from various clinical samples like urine, pus, sputum, blood and other body fluid received in microbiology laboratory, Mandya institute of medical science, Mandya.

\section{Method of collection of data}

The collected samples were inoculated onto MacConkey agar, Blood agar, Mannitol salt agar \&incubated at $37^{\circ} \mathrm{c}$ for $24-48$ hours. Yellow colonies from MSA were sub cultured on Nutrient agar. Staphylococcus aureus were identified and confirmed by Catalase test, Gram's staining and Coagulase test (Slide and tube) with respective controls using golden yellow colonies from Nutrient agar.A total of 150 isolates of Staphylococcus aureus thus obtained were screened for MRSA. 


\section{Antimicrobial susceptibility test}

Antibiotic susceptibility testing was performed by Kirby-Bauer disk diffusion method as per CLSI Guidelines. Antimicrobial discs used were Penicillin (10 units), Co-trimoxazole $(25 \mu \mathrm{g}), \quad$ Linezolid $(30 \mu \mathrm{g})$,Vancomycin $(30 \mu \mathrm{g})$, Chloramphenicol $(30 \mu \mathrm{g})$, Cefoxitin $(30 \mu \mathrm{g})$, Clindamycin $(2 \mu \mathrm{g})$, Erythromycin $(15 \mu \mathrm{g})$, Tetracycline $(30 \mu \mathrm{g})$, Ciprofloxacin $(5 \mu \mathrm{g})$, Gentamicin $(10 \mu \mathrm{g})(\mathrm{Hi}$ media Pvt.Ltd., Mumbai, India). ${ }^{7}$

All the isolates whose Zone diameter less than $21 \mathrm{~mm}$ for Cefoxitin $(30 \mu \mathrm{g})$ disc were considered as MRSA and zone diameters greater than $21 \mathrm{~mm}$ were considered as MSSA as per CLSI guidelines. ${ }^{7}$ Linezolid resistance on MRSA was carried out using Kirby-Bauer disk diffusion method, Epsilomer test and Broth micro dilution method as per CLSI guidelines. Zone diameter less than $21 \mathrm{~mm}$ for linezolid were considered resistant by KirbyBauer disk diffusion method.

\section{Statistical analysis}

Data was entered into Microsoft excel data sheet and was analysed using SPSS 22 version software. Categorical data was represented in the form of Frequencies and proportions.

\section{Results and Discussion}

Table.1 Age wise Distribution of MRSA and MSSA

\begin{tabular}{|c|c|c|c|}
\hline Age groups & MRSA (\%) & MSSA (\%) & Total \\
\hline$\leq \mathbf{1 4 y r s}$ & $8(80.0)$ & $2(20.0)$ & 10 \\
\hline $\mathbf{1 5 - 3 0 y r s}$ & $14(33.3)$ & $28(66.7)$ & 42 \\
\hline 31-60yrs & $30(41.1)$ & $43(58.9)$ & 73 \\
\hline$\geq \mathbf{6 0 y r s}$ & $13(52.0))$ & $12(48.0)$ & 25 \\
\hline Total & $\mathbf{6 5}$ & $\mathbf{8 5}$ & $\mathbf{1 5 0}$ \\
\hline
\end{tabular}

Above table shows that majority of MRSA isolated were in the age group $<14$ yrs showing $80 \%$, followed by age group $>60$ yrs showing 52\%,age group between 31-60yrs showing $41.1 \%$ and least $33.3 \%$ between 15 30 yrs.

Table.2 Gender wise distribution of MRSA \& MSSA

\begin{tabular}{|c|c|c|c|}
\hline Gender & MRSA (\%) & MSSA (\%) & Total \\
\hline Male & $44(53.0)$ & $39(47.0)$ & 83 \\
\hline Female & $21(31.3)$ & $46(68.7)$ & 67 \\
\hline Total & $\mathbf{6 5}$ & $\mathbf{8 5}$ & $\mathbf{1 5 0}$ \\
\hline
\end{tabular}

In the present study, 150 Staphylococcus aureus were screened for MRSA. Out of 150 isolates, $65(43.3 \%)$ were MRSA and 85 $(56.7 \%)$ were MSSA. Out of 65 MRSA isolates, males have higher prevalence of
$67.7 \%$ compared to females showing $32.3 \%$.Out of 85 MSSA isolates, females have higher prevalence of $45.9 \%$ compared to males showing $54.1 \%$. 
Table.3 Distribution of MRSA and MSSA among the clinical samples

\begin{tabular}{|c|c|c|c|}
\hline Samples & MRSA (\%) & MSSA (\%) & Total \\
\hline Urine & $6(40.0)$ & $9(60.0)$ & 15 \\
\hline Pus & $48(41.4)$ & $68(58.6)$ & 116 \\
\hline Sputum & $11(61.1)$ & $7(38.9)$ & 18 \\
\hline Throat swab & 0 & $1(100)$ & 01 \\
\hline Total & $\mathbf{6 5}$ & $\mathbf{8 5}$ & $\mathbf{1 5 0}$ \\
\hline
\end{tabular}

Out of 150 isolates, $116(77.3 \%)$ were isolated from pus, 18 (12\%) from sputum, $15(10 \%)$ from urine and $1(0.7 \%)$ from throat swab. Out of 65 MRSA, $48(73.8 \%)$ were isolated from pus,11(16.9\%) from sputum,
$6(9.3 \%)$ from urine. Out of 85 MSSA, $68(80 \%)$ were isolated from pus, $9(10.6 \%)$ from urine, $7(8.2 \%)$ from sputum and $1(1.2 \%)$ from throat swab.

Table.4 Antibiogram of MRSA isolates

\begin{tabular}{|c|c|c|}
\hline \multirow{2}{*}{ Antibiotics } & \multicolumn{2}{|c|}{ MRSA( $=65)$} \\
\cline { 2 - 3 } & Sensitive (\%) & Resistant (\%) \\
\hline Penicillin-G & - & $65(100)$ \\
\hline Vancomycin & $65(100)$ & - \\
\hline Cotrimoxazole & $37(56.9)$ & $28(43.1)$ \\
\hline Linezolid & $65(100)$ & - \\
\hline Rifampicin & $49(75.4)$ & $16(24.6)$ \\
\hline Clindamycin & $38(58.5)$ & $27(41.5)$ \\
\hline Teicoplanin & $65(100)$ & - \\
\hline Chloramphenicol & $34(52.3)$ & $31(47.7)$ \\
\hline Erythromycin & $46(70.8)$ & $19(29.2)$ \\
\hline Gentamycin & $37(57.0)$ & $28(43.0)$ \\
\hline Ciprofloaxacin & $40(61.5)$ & $25(38.5)$ \\
\hline Ofloxacin & $30(46.2)$ & $35(53.8)$ \\
\hline Nitrofurtion (for urine samples only) & $3(50.0)$ & $3(50.0)$ \\
\hline
\end{tabular}

Out of 65 MRSA, Penicillin-G shows $100 \%$ resistance followed by Ofloxacin $53.8 \%$ and Chloramphenicol 47.7\%. Vancomycin, Teicoplanin and Linezolid showed 100\% sensitivity followed by Rifampicin $75.4 \%$, Erythromycin $70.8 \%$ and Ciprofloxacin $61.5 \%$.
In our study out of 150 clinical isolates 65(43.3\%) were MRSA and 85(56.7\%) were MSSA in comparison with the study conducted by Sanjana et al., ${ }^{8}$ showing $39.6 \%$ MRSA and by kshetry et al., ${ }^{9}$ with $37.6 \%$. Out of 65 MRSA, majority of isolates were isolated from age group less than 14 years 
with $80 \%$ followed by age group more than 60 years with $52 \%$ in comparison with Shakya et al., ${ }^{10}$ showing $79 \%$ below 14yrs and $48 \%$ above 60 yrs.

Similar findings were observed in a study conducted by Rachel J Gorwiz et al., ${ }^{11}$ showing $72 \%$ below $14 \mathrm{yrs}$ and $47 \%$ above 60 yrs.

This result indicates that the extreme of the ages were more prone to get MRSA infection due to weak immune system. Sharma et al., ${ }^{12}$ also noted that extreme of the ages were prone to get MRSA infection. The age group between 30-60 years have $52 \%$ of prevalence in our study which is comparable to the study conducted by Mehrdad Askarian et al., showing high prevalence in the age group from $30-50 y r s$ with $62.5 \%$

The age group between 15-30 years shows MRSA prevalence with $33.3 \%$ in comparison with the study of Rachel $\mathrm{J}$ Gorwiz et al., ${ }^{11}$ with $13.3 \%$.

In the Present study, Out of $83(55.3 \%)$ males and $67(44.6 \%)$ females screened from 150 isolates, 44(67.7\%) MRSA were isolated from males and 21(32.3\%) were isolated from females.

In comparison with our study, the study conducted by Nadia aslam et al., ${ }^{10}$ shows majority of MRSA were isolated from male patients with $65.2 \%$ and female with $34.8 \%$

Similar findings were seen even in the study conducted by Rezvanmoniri et al., ${ }^{14}$, which shows male having higer prevalence than female with percent of 61 in male and 39 in female. Mathanraj et al., ${ }^{15}$, in his study found that prevalence of MRSA is more in male than the females. They also suggested that, this may also be due to more outdoor activities by males compared to females.
High prevalence were also reported in the study conducted by Hussain et al., ${ }^{16}$ showing $66.25 \%$, Sasirekha et al., ${ }^{17}$ showing $57.7 \%$ MRSA, Tiwari et al., ${ }^{18}$ showing $69.1 \%$ and Khanal et al., ${ }^{19}$ showing 68\%.Low prevalence was also noted in the study conducted by Baral et al., ${ }^{20}$ showing $26 \%$, Subedi and Brahmadathan et al., ${ }^{21}$ showing 15.4\%.Different studies show different rate of isolation of MRSA,this might be due to antibiotic policy \& antibiotic pressure vary from hospital to hospital, different time period of studies and difference in their location. Difference in the socioeconomic status of study group between hospitals.

Vancomycin seems to be the only antimicrobial agent which showed 100\% sensitivity and may be used as the drug of choice for treating multidrug resistant MRSA infections. However, regular monitoring of vancomycin sensitivity, and routine testing of other newer glycopeptides like teicoplanin should be carried out. Further, the regular surveillance of hospital associated infections including monitoring antibiotic sensitivity pattern of MRSA and formulation of definite antibiotic policy may be helpful for reducing the incidence of MRSA infection.

\section{Acknowledgements}

Authors would like to acknowledge all the subjects participated in the study. Everyone who contributed in the completion of the study including the technical staff

\section{References}

1. Lowy FD. Staphylococcus aureus infection. New Engl Jour Med. 1998;339:520-32.

2. 2. Waldvogel FA. Staphylococcus aureus. In: Mandell GL, Bennett JE, Dolun $\mathrm{R}$, Livingstone $\mathrm{C}$, editors. In principles and practice of infectious 
diseases. Philadelphia Pennsylvania USA; 2000: 2069-2092.

3. 3. Kapil A, Sharma A, Thomas PA, editors. Ananthanarayan \& Paniker's Textbook of Microbiology, 9th Edition. Universities Press; 2013: 199207.

4. 4. Elmer $\mathrm{K}$, Washington $\mathrm{W}$, StaphenA, Gary P, editors. Color Atlas \& Textbook of Diagnostic Microbiology, 6th edition. Wolters Kluwer; 2006: 643-648.

5. Fitzgerald JR, Sturdevant DE, Mackie SM, Gill SR, Musser JM: Evolutionary genomics of Staphylococcus aureus: insights into the origin of methicillin-resistant strains and the toxic shock syndrome epidemic. Proc. Natl Acad. Sci. USA2001; 98(15): 8821-8826

6. Mansouri S, Khaleghi M. Antibacterial resistance pattern and frequency of methicillin resistant Staphylococcus aureus.Iranian J Med Sci1997;22:93.

7. Clinical and Laboratory Standards Institute. Methods for Dilution Antimicrobial Susceptibility Tests for Bacteria that Grow Aerobically. Approved Standard. 8th ed. Wayne, PA: CLSI Document M7-A8. CLSI; 2018

8. R. Sanjana, R. Shah, N. Chaudhary, and Y. Singh, "Prevalence and antimicrobial susceptibility pattern of methicillin-resistant Staphylococcus aureus (MRSA) in CMS-teaching hospital: a preliminary report," Journal of College of Medical Sciences-Nepal 2010;6(1): 1-6.

9. A. O. Kshetry, N. D. Pant, R. Bhandari et al., "Minimum inhibitory concentration of vancomycin to methicillin resistant Staphylococcus aureus isolated from different clinical samples at a tertiary care hospital in
Nepal," Antimicrobial Resistance \& Infection Control 2016;5(1): article 27.

10. Shakya B, Shrestha S, Mitra T. Nasal carriage rate of Methicillin resistant Staphylococcus aureus among at National Medical College Teaching Hospital, Birgunj, Nepal. Nepal Med Coll J 2010;12:26-9

11. Gorwitz RJ, Jernigan JA. Epidemiology of communityassociated Staphylococcus aureus infections. In: Crossley KB, Jefferson KK, Archer GL, Fowler Jr VG (eds.), Staphylococci in human disease. 2nd ed. London: Wiley-Blackwell; 2009: 272-89

12. Sharma Y, Jain S, Singh H, Govil V. Staphylococcus aureus: Screening for nasal carriers in a community setting with special reference to MRSA. Sceintifica 2014;479048.

13. Askarian M, Zeinalzadeh A, Japoni A, Alborzi A, Ziad A. Memish Prevalence of nasal carriage of methicillin-resistant Staphylococcus aureus and its antibiotic susceptibility pattern in healthcare workers at Namazi Hospital, Shiraz, Iran International Journal of Infectious Diseases 2009;13:241-7

14. Moniri R, Musav GA, Fadavi N. The prevalence of nasal carriage methicillin resistant Staphylococcus aureus in hospitalized patients. Pak J Med Sci 2009;25(4):656-9

15. Mathanraj S, Sujatha S, Sivasangeetha K, Parija SC Screening for methicillin resistant Staphylococcus aureus carriers among patients and health care workers of a tertiary care hospital in South India. Indian Journal of Medical Microbiology 2009;27(1):624.

16. Hussain JH, Thakur A, Mishra B, Dogra V, Jaggi T. Antimicrobial 
susceptibility pattern of methicillinresistant strains of Staphylococcus aureus in a super specialty hospital. Int J Health Allied Sci. 2015;4:69-72.

17. Sasirekha B, Usha MS, Amrutha AJ, Ankit S, Brinda N, Divya R. Evaluation and comparison of different phenotypic tests to detect methicillin resistant Staphylococcus aureusand their bioflim production. Int J PharmTech Res. 2012;4:532-41.

18. H. K. Tiwari, A. K. Das, D. Sapkota, K. Sivarajan, and V. K. Pahwa, "Methicillin resistant Staphylococcus aureus: prevalence and antibiogram in a tertiary care hospital in western Nepal," Journal of Infection in Developing Countries,2009;3(9): 681684.
19. L. K. Khanal and B. K. Jha, "Prevalence of methicillin resistant Staphylococcus aureus (MRSA) among skin infection cases at a hospital in Chitwan, Nepal," Nepal Medical College Journal, 2010;12(4):224-228.

20. R. Baral, B. Khanal, and A. Acharya, "Antimicrobial susceptibility patterns of clinical isolates of Staphylococcus aureus in EasternNepal,"Health Renaissance 2011; 9(2): 78-82

21. Sasirekha B, Usha MS, Amrutha AJ, Ankit S, Brinda N, Divya R. Evaluation and comparison of different phenotypic tests to detect methicillin resistant Staphylococcus aureusand their bioflim production. Int J PharmTech Res. 2012;4:532-41.

\section{How to cite this article:}

Sharlee. R and Sumangala. B. 2020. Prevalence of Methicillin Resistance Staphylococcus aureus in Teaching Hospital, Karnataka. Int.J.Curr.Microbiol.App.Sci. 9(03): 2837-2843. doi: https://doi.org/10.20546/ijcmas.2020.903.327 